\title{
Restoration of the striatal circuitry: from developmental aspects toward clinical applications
}

\author{
Marie-Christin Pauly ${ }^{1}$, Tobias Piroth ${ }^{2}$, Máté Döbrössy ${ }^{1}$ and Guido Nikkhah ${ }^{1}$ \\ Division of Stereotactic Neurosurgery, Department of General Neurosurgery, University Freiburg - Medical Center, Freiburg im Breisgau, Germany \\ 2 Department of Neurology, University Freiburg - Medical Center, Freiburg im Breisgau, Germany
}

\author{
Edited by: \\ Afsaneh Gaillard, University of \\ Poitiers, France \\ Reviewed by: \\ Stephen B Dunnett, Cardiff \\ University, UK \\ Abdellatif Benraiss, University of \\ Rochester, USA \\ *Correspondence: \\ Marie-Christin Pauly, Division of \\ Stereotactic Neurosurgery, \\ Department of General \\ Neurosurgery, University Freiburg - \\ Medical Center, Breisacher Str. 64 . \\ D-79106 Freiburg im Breisgau, \\ Germany. \\ e-mail:marie-christin.pauly@ \\ uniklinik-freiburg.de
}

In the basal ganglia circuitry, the striatum is a highly complex structure coordinating motor and cognitive functions and it is severely affected in Huntington's disease (HD) patients. Transplantation of fetal ganglionic eminence (GE) derived precursor cells aims to restore neural circuitry in the degenerated striatum of HD patients. Pre-clinical transplantation in genetic and lesion HD animal models has increased our knowledge of graft vs. host interactions, and clinical studies have been shown to successfully reduce motor and cognitive effects caused by the disease. Investigating the molecular mechanisms of striatal neurogenesis is a key research target, since novel strategies aim on generating striatal neurons by differentiating embryonic stem cells or by reprogramming somatic cells as alternative cell source for neural transplantation.

Keywords: striatum, Huntington's disease, development, ganglionic eminence, transplantation

\section{ANATOMY OF THE ADULT STRIATUM}

The striatum, sometimes referred as Neostriatum or Corpus Striatum, is located at the ventral part of the telencephalon where it coordinates cognitive and motor impulses between basal ganglia and cerebral cortex. The term striatum (Latin striatus $=$ striped) describes two brain nuclei sharing the same ontogenic origin in the telencephalic primordium: the putamen (Latin puta$m e n=$ stone in a fruit) and caudate nucleus (Latin cauda $=$ tail). Located in the ventral telencephalon adjacent to the lateral ventricles, the central round putamen is ensheathed by the C-shaped caudate nucleus at its dorsal part. The ventrorostral part where the head of the caudate nucleus and the anterior putamen are fused is referred as Nucleus accumbens. Due to its connectivity within the mesolimbic pathway, the Nucleus accumbens is rather considered as interface between basal ganglia and limbic system. In the human brain, putamen and caudate nucleus appear as two individual structures separated by the dense fiber tracts of the internal capsule, whereas in the rodent brain the separation of caudate nucleus and putamen is less evident because fibers of the internal capsule appear more distributed throughout the striatum.

\section{NEURONAL CELL TYPES AND PROJECTIONS OF THE STRIATUM}

The striatum consists of about $96 \%$ projection neurons. Striatal projection neurons have a medium-sized soma $(\sim 10-15 \mu \mathrm{m}$ in diameter), a long extending axon and number of dendrites with densely packed spines which is why they are referred as medium spiny neurons (MSN). Medium spiny projection neurons release the inhibitory neurotransmitter $\gamma$-amino butyric acid (GABA), as well as different neuropeptide transmitters such as Enkephalin,
Dynorphin, and Substance P (Kawaguchi et al., 1995; Kawaguchi, 1997).

Based on their projection sites, MSNs can be divided into two populations. The first population projects directly from the striatum to the substantia nigra pars reticulata $(\mathrm{SNr})$ and the internal segment of the globus pallidus (GPi). This projection is referred as the direct pathway, since it directly projects the basal ganglia output nuclei. The second population also projects to the $\mathrm{SNr}$ and GPi, but indirectly via several intermediate relays in the external part of the globus pallidus (GPe) and the subthalamic nucleus and is referred as the indirect pathway. Neurons projecting in the direct or indirect pathway are equal in proportion among striatal neurons. Interestingly, neurons of both populations can be distinguished based on their peptide transmitters on the one hand and their dopamine receptors on the other hand (Le Moine and Bloch, 1995; Durieux et al., 2011). Neurons of the direct pathway release Substance P and Dynorphin as co-transmitters and express type 1 dopamine receptors predominantly. Upon dopamine release from the substantia nigra pars compacta $(\mathrm{SNc})$, neurons that express this receptor type become activated and release GABA to the SNr. Striatal projection neurons of the indirect pathway express type 2 dopamine receptors and release Enkephalin as a co-transmitter. Type 2 dopamine receptor positive neurons become inhibited once dopamine is released from the SNc. Thus, dopamine has different effects on striatal neurons: depending on their projection sites, MSNs become either activated or inhibited by the release of dopamine.

Furthermore, about $4 \%$ of the striatal neurons are aspiny interneurons, with about 3\% cholinergic interneurons, and $1 \%$ GABAergic interneurons. Among the GABAergic interneurons, 
three populations can be distinguished based on the neuropeptides Somatostatin, Calretinin, and Parvalbumin which serve as co-transmitter. In addition to co-transmitter phenotypes, GABAergic interneurons can be distinguished by their firing behavior. Parvalbumin expressing interneurons are fast spiking, whereas Somatostatin positive interneurons are characterized by low threshold calcium spikes (LTS). For Calretinin positive striatal interneurons a persistent and low-threshold spiking (PLTS) has been postulated (Tepper and Bolam, 2004). Besides cotransmitters and firing behavior, striatal projection neurons as well as GABAergic and cholinergic interneurons can be distinguished by their nuclear morphology and heterochromatin distribution using TO-PRO3 staining (Matamales et al., 2009).

\section{STRIATAL AFFERENTS}

In addition to their target projection, striatal neurons can also be classified by the specific inputs they receive. MSN receive dopaminergic input from the SNc. Furthermore, MSN are also innervated by cortical and thalamic neurons (Gerfen, 1989, 1992). Excitatory glutamatergic innervation from the cortex to the striatum occurs mainly from limbic cortical areas in layer IV and the premotor cortex in layer V. Dopaminergic innervation of striatal neurons is established earlier in development than cortical and thalamic innervation. The cortical input from layer IV and layer $\mathrm{V}$ results in a morphological pattern that is referred as striosomematrix subdivision. Striatal striosomes (sometimes also referred as striatal patches) are MSN, receiving dopaminergic input from the SNc and glutamategic input from limbic cortical areas of layer $\mathrm{V}$. These striosomes form small clusters of neurons about 150$300 \mu \mathrm{m}$ in diameter and are embedded in the so-called matrix. Matrix neurons are projection neurons receiving input from the occulomotor and sensorimotor cortex as well as input from the thalamus. Besides the above mentioned neurochemical markers, striatal patches are characterized by the presence of the $\mu$-opiate receptor 1 ( $\mu$ OR-1), whereas matrix neurons are characterized by the presence of the calcium-binding protein Calbindin.

\section{EMBRYONIC DEVELOPMENT OF THE STRIATUM}

Ontogenetically, the striatum and the adjacent globus pallidus originate from the same anlage that is located at the ventral portion in each hemisphere of the developing telencephalon. This anlage is called ganglionic eminence (WGE = whole ganglionic eminence) and consists of three primordia which are referred as lateral ganglionic eminence (LGE), medial ganglionic eminence (MGE), and caudal ganglionic eminence (CGE). The WGE appears at embryonic day E10.5 in rat fetuses and at about 42 days post conception in the human fetus. The WGE is subdivided into three functional areas: the upper layer that contacts the lateral ventricle, is the so-called ventricular zone (VZ), the underlying layer is referred as subventricular zone (SVZ) and contains proliferating neural precursors. The central area where maturating neurons are located is called mantle zone (MZ). The area between $\mathrm{MZ}$ and SVZ is referred as intermediate zone (IZ).

\section{PROLIFERATION AND CELL MIGRATION IN THE GANGLIONIC EMINENCE}

Originating from a single central eminence that bulges into each lateral ventricle, neuronal precursors start to proliferate and migrate radially so that a second eminence appears lateral to the first eminence at about E12.5 in the rat fetus. The first appearing eminence will give rise to the MGE, while the second one develops into the LGE. In the rostral region, the two eminences are separated by a rostro-caudal furrow, but in the caudal region, both eminences are fused and give rise the so-called CGE (Hamasaki et al., 2003). The proliferation of SVZ precursors in which the LGE is generated is referred as early phase of neurogenesis. The early phase of neurogenesis ends at about E14.5 in the rat fetus. Subsequently, fibers extending from cerebral cortex reach the newly generated striatal precursors, and thus generate the corticostriatal pathway.

A second phase of neurogenesis can be observed between E17.5 and P2 in the rat fetus which is referred as late phase of striatal neurogenesis. During that phase, proliferating precursors migrate into the outer MZ toward the already existing neurons generated during early neurogenesis that receive cortical input. The early born striatal neurons are not equally separated by the migrating late-born neurons; they rather remain grouped in cell clusters (Krushel et al., 1995). Due to the incomplete separation between early and late stage striatal neurons, a pattern appears that can be observed until adulthood: the striosome and matrix compartments. Striatal neurons located in the striosome were generated during early neurogenesis, while neurons of the matrix compartment were generated during late neurogenesis. Late-born (matrix) striatal neurons receive cortical input independent and different from the cortical input that early-born (striosomal) striatal neurons receive. Thus, birth-dating results in a different cortical innervation pattern and subsequently, in a different functionality of striatal neurons.

\section{GENETIC CONTROL OF STRIATAL DEVELOPMENT}

The development of the striatum is strictly controlled by intrinsic and extrinsic molecular cues. Priming of ventral telencephalic cells begins in the neural tube at about E9 in the rat fetus. Cells located in the ventral neural tube receive Sonic hedgehog (Shh) signals from the underlying prechordal plate and the ventral neural tube itself. While at the same time, cells of the anterior neural tube receive the Wnt-antagonizing molecule Dickkopf-1 (Dkk-1) as well as the fibroblast growth factor-8 (Fgf8), both secreted by the anterior commissural plate. Downstream actors of Shh are the homeobox proteins Gsx2 (also Gsh2) and Nkx2-1 (also TTF-1) (Figure 1A). Nkx2-1 is expressed in the medial portion of the ventral forebrain, whereas Gsx2 is expressed lateral to the Nkx2-1 domain (Corbin et al., 2003). In the rat E10 fetal telencephalon, both expression domains are separated, but Gsx2 and Nkx2-1 expression domains overlap coincident with the appearance of the GE. Besides the expression of these two homeodomain proteins, Fgf8 and Shh pathway induce the expression of the forkhead transcription factor Foxg1 (also referred as brain factor 1, Bf1) at about E10 in the rat fetus (Shimamura and Rubenstein, 1997; Martynoga et al., 2005; Paek et al., 2009). Cells positive for Foxg1 act autonomously during striatal development. Gsh2 induces the expression of Mash1 (also referred as Ascl-1) in the ventral forebrain.

Mash1 is the mammalian homolog of the Drosophila melanogaster neurogenic gene achate-scute. This is one key 

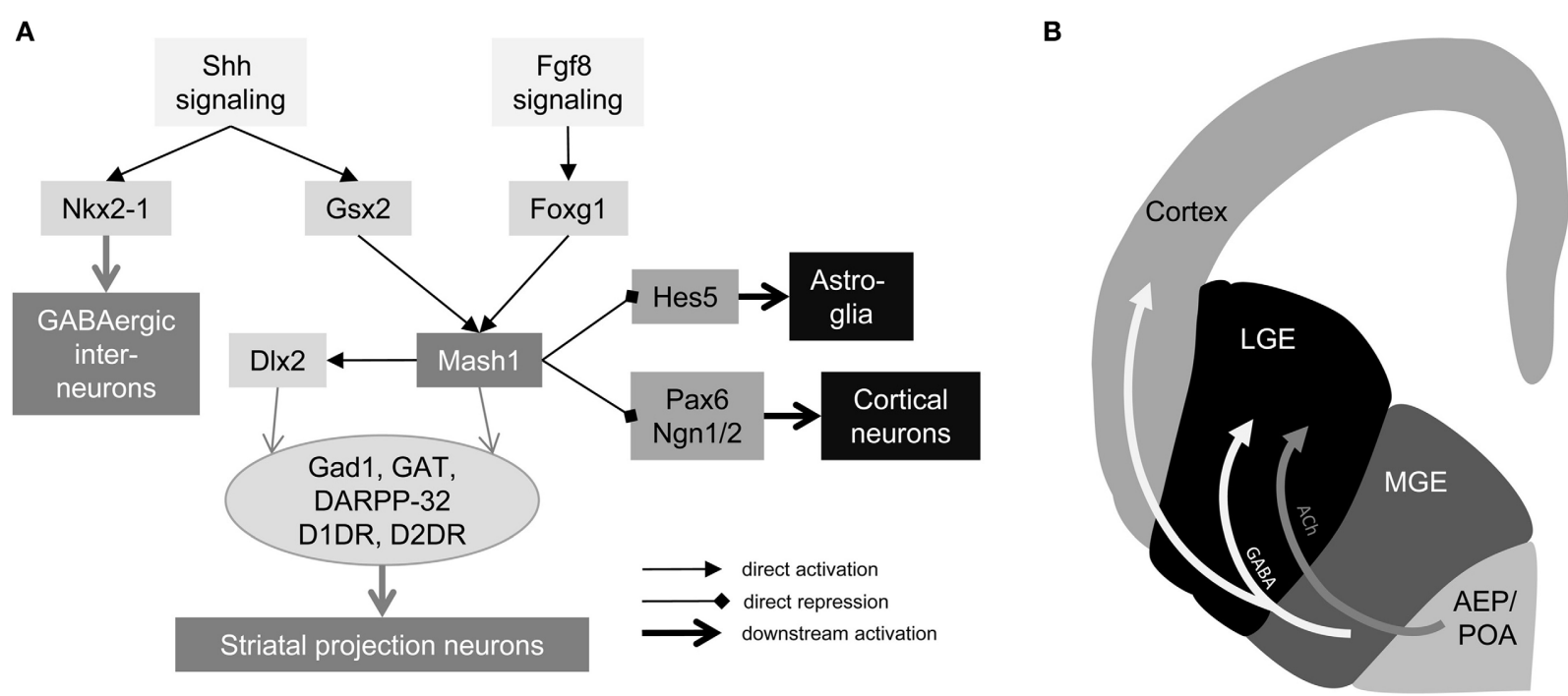

FIGURE 1 | Genetic control and cell migration in the ventral telencephalon. (A) Gene regulatory network of striatal neurogenesis. Secreted factors Fgf8 and Shh activate expression of early forebrain factors Nkx2-1, Gsx2, and Foxg1. Gsx2 and Foxg1 regulate expression of Mash1, which activates Dlx2 and suppresses astrocyte lineage via Hes5 and cortical lineage via Pax6 and Ngn1/2. Mash1 and Dl×2 generate GABAergic projection neurons in the ventral forebrain and Nkx2-1 is involved in interneuron formation in the MGE. (B) Tangential cell migration in the fetal forebrain.
Schematic drawing of a coronal section of a rat E14 fetal forebrain (left hemisphere). Light gray arrow indicates tangential cell migration of acetylcholinergic precursors from the AEP/POA to the LGE. White arrows indicate migration of GABAergic progenitors from the MGE to the LGE and cortex. ACh: acetylcholine, AEP: anterior entopeduncular area, D1DR: dopamine receptor D1, D2DR dopamine receptor D2, Gad1: glutamate decarboxylase 1; GAT: GABA transporter, LGE: lateral ganglionic eminence, MGE medial ganglionic eminence, POA: preoptic area. transcriptional regulator of neuronal development, especially in neuron vs. astrocyte fate decision. More specifically, Mash1 is expressed in brain regions supposed to adopt a GABAergic phenotype. It plays an important role in the development of ventral fore- and midbrain, as well as in the developing spinal cord. The protein has a basic-helix-loop-helix DNA binding motif and can interact with other proteins sharing the same motif to conjointly bind the DNA. Besides inducting GABAergic fates in the ventral forebrain, the second major role that Mash1 plays is to repress dorsal telencephalon-specific factors like Pax6, Neurogenin1, and Neurogenin2. Besides Mash1, there is a second key regulator in striatal neurogenesis: Dlx2. Foxg1 and Gsx2 have been assumed to induce the expression of Dlx2 due to abnormal expression in mutant embryos. Furthermore, is has been shown that Mash 1 directly regulates the expression of Dlx2 by interacting with the Dlx2 enhancer (Poitras et al., 2007). Dlx2 is a member of the distal-less gene family with six known members in the mammalian genome, four of them $(D l x 1,2,5,6)$ are involved in striatal development. The homeodomain protein Dlx2 is specifically expressed in the LGE and MGE staring from E11 in the rat fetus. Dlx2 has been associated with forebrain GABAergic specification. Expression analysis of Dlx2 mutant embryos revealed that Dlx2 regulates genes for GABA synthesis (Gad1) and transport (GAT) as well as expression of dopamine receptors (Long et al., 2009a,b). Furthermore, Dlx2 has been associated with matrix neurogenesis, while, in turn, Mash1 has been associated with generation of striosomal neurons. Therefore, it seems that the striosome-matrix pattern is defined by birth dating and input projections, as well as intrinsically. This idea is supported by work that has published by Passante and co-workers who showed that striatal patterning depends on direct cell-cell contract involving ephrins and Eph receptors. Double knock-out of the ephrinA5 ligand and EphA4 receptor displayed aberrant striatal patterning (Passante et al., 2008).

While striatal projection neurons are mainly generated in the LGE, GABAergic interneurons are generated in the MGE and cholinergic interneurons are generated in the medial located anterior entopeduncular area (AEP), respectively, anterior preoptic area (POA) form where they migrate to their target in the LGE (Figure 1B) (Marin et al., 2000; Marín and Rubenstein, 2001). In the MGE, not only striatal interneurons are generated, but also cortical interneurons. Nkx2-1 that is expressed in the MGE until E18 in the rat fetus plays an important role in striatal vs. cortical interneuron sorting. Depending on the time point of Nkx2-1 down regulation cells either migrate toward the LGE or cortical anlage (Nóbrega-Pereira et al., 2008).

Besides neurotransmitter release, areas projecting to the striatum supply neurotrophins that are essential for survival of striatal neurons. Dopaminergic cells from the SN secrete GDNF (glial derived neurotrophic factor) which acts via the GDNF receptors $\alpha 1$ and $\alpha 2$. Cortical terminals secrete BDNF (brain-derived neurotrophic factor) which binds the TrkB receptor that is prevalently expressed by striatal neurons of the indirect pathway. Aberrant BDNF signaling due to mutations in the TrkB receptor or one of the downstream effector molecules leads to selective loss of striatal projection neurons (Baydyuk et al., 2011). In good agreement with this observation, Huntingtin (htt) mutations have been shown to alter TrkB-mediated cell growth and survival providing a principle cause for striatal atrophy in the diseased brain (Zuccato et al., 2001). 


\section{DIFFERENTIATING STEM CELLS INTO STRIATAL NEURONS}

Several attempts have been made to generate striatal neurons from pluripotent embryonic stem cells (ESC). In 2008, Aubry and co-workers presented a three- step protocol for the induction of striatal neurons (Aubry et al., 2008). Initially, human ESCs are pre-differentiated into neuronal rosettes on MS5 mouse feeder cells. In a second step, the ventral telencephalic phenotype is induced by growth factor treatment including Dkk-1, Shh, and BDNF. Finally, maturation of striatal neurons is achieved by combined treatment of BDNF, valproic acid, and cAMP. Using this protocol, the authors successfully differentiated striatal precursors from pluripotent human ESC and showed that these cells mature into functional striatal neurons. Furthermore, induced pluripotent stem cells (iPS) derived from skin fibroblasts from Huntington's disease patients (HD-iPS) were successfully differentiated into GABAergic neurons using a similar protocol. These cells were also positive Calbindin and DARPP-32 (dopamine- and cyclic AMP-regulated phosphoprotein, $\mathrm{MW}=32 \mathrm{kDa}$ ) ensuring a striatal phenotype (Zhang et al., 2010).

In 2010, Vierbuchen and colleagues proved the direct conversion of skin fibroblasts into functional neurons (Vierbuchen et al., 2010). Conversion of fibroblasts can be achieved by forced overexpression of pro-neuronal genes including Mash1. These so-called induced neurons (iN) display a general neuronal phenotype and are able to form synapses and fire action potentials. More specifically, skin fibroblasts could be converted into midbrain dopaminergic neurons (Caiazzo et al., 2011; Pfisterer et al., 2011). Those cells were generated by combined overexpression of general pro-neuronal and midbrain-specific transcription factors. These results prove that induction of a specific neuronal phenotype is generally possible. Although not realized yet, it is very likely that the conversion of fibroblasts into striatal neurons can be achieved in a similar way using general neuronal transcription factors like Mash1 in combination with WGE-specific factors. These results provide a promising approach for the treatment of neurodegenerative diseases such as Parkinson's disease (PD) and HD.

\section{PRECLINICAL NEURAL TRANSPLANTATION IN HD ANIMAL MODELS OF HD}

Animal models of human brain diseases are imperfect, but important scientific tools helping to learn more about diseases, their pathology, etiology, underlying neurobiological and behavioral aspects. Furthermore, they can offer a platform to develop therapeutic avenues that could be translated to the clinic.

HD is a genetically inherited, autosomal dominant disease caused by the expansion of the CAG repeats in exon 1 of the $\mathrm{htt}$ gene (The Huntington's Disease Collaborative Research Group, 1993). The disease severely affects numerous regions of the brain, particularly the medium spiny striatal projection neurons, and is associated with motoric and cognitive pathology (Ross and Tabrizi, 2011). There are two categories of animal models available in pre-clinical HD research: genetically modified and lesion models. Both of these approaches result in modeling various neuropathological, metabolic, and behavioral symptoms of HD such as dysfunction and degeneration of striatal neurons, and motoric and cognitive deficits. Below is a summary of the models that are relevant in the field of cell therapy, otherwise animals models for HD have been extensively reviewed elsewhere (Cenci et al., 2002; Ramaswamy et al., 2007).

\section{Genetically modified models}

The identification of the mutant $h t t$ gene has permitted the establishment of a variety of genetically modified rodent models (mainly in mice, but some in rats) including transgenic, knockin, knock-out, and virally inserted poly-glutamine tract models (Wang and Qin, 2006; Heng et al., 2008). Genetically modified models have a lot of face validity and authenticity as they are constructed on the same rationale that lies behind the pathology present in humans: the genetic mutation in the htt gene that causes HD. These models are ideal for studying cellular and molecular aspects of the disease (Crook and Housman, 2011). However, there are significant differences between models of genetically modified animals regarding the behavioral and cellular consequences of the expression of the mutant gene, the rate of onset of the pathology, the distribution pattern of the inclusions, the degree of neuronal death, and expected life span of the animals. For this reason, genetically modified models are typically not used to study the viability of neural transplantation in HD: issues concerning the restoration of GABAergic circuitry are traditionally addressed using lesion models as this allows for a more precise control of when and where striatal projection neurons should degenerate.

\section{Excitotoxic lesion models}

Over the years, two main types of excitotoxic cell deaths have been described: indirect and direct. Indirect, or secondary, excitotoxicity is process by which cells are made vulnerable first which then leads to excitotoxic neuronal death mediated by otherwise sub-toxic glutamate. The mechanism implicated is metabolic or oxidative stress and is dependent on a progressive impairment of neuronal mitochondria-based energy metabolism (Beal, 1998). Common agents that have been used to generate animal models of HD by inducing secondary excitotoxicity are the metabolic toxins malonate and 3-nitropropionic acid (Beal et al., 1993; Brouillet et al., 1993; Henshaw et al., 1994; Roitberg et al., 2002). Direct, or primary, excitotoxicity can be induced by excessive or prolonged glutamate receptor activation. In animal models of $\mathrm{HD}$, this is done using stereotactic neurosurgery methods as only this way can one induce acute neuronal loss in a highly precise and selective fashion in the rodent CNS using glutamate analogs such as kainic, ibotenic, or quinolinic acids (Coyle and Schwarcz, 1976; Schwarcz et al., 1979, 1980, 1983, 1984; Beal et al., 1991; Beal, 1992). The underlying mechanisms of glutamate receptor mediated toxicity are complex but excessive calcium influx (Choi, 1987; Tymianski et al., 1993) is a major factor, and neuronal death occurs via both necrotic and apoptotic pathways (Lau and Tymianski, 2010).

Over the past decade, quinolinic acid has emerged as the excitotoxin of choice in lesion models of HD due to the reproducibility of cell loss, and its selectivity for striatal neurons. The selectivity is explained by the toxin's high affinity for the NMDA receptors found on post-synaptic membranes of specific striatal 
neurons. Importantly, models using quinolinic acid lesions have been shown to replicate the features of HD pathology well, including the differential vulnerability of striatal neurons such as the depletion of GABA and Substance P positive neurons, but sparing of Somatostatin and Neuropeptide Y positive neuronal subpopulations that typically co-localize with NADPH-diaphorase (Beal et al., 1986, 1989). By carefully manipulating the lesion parameters such as the volume, dose, infusion rate, lesioning location, and the number of lesion sites, the cellular and behavioral impact of the toxin can be controlled. Quinolinic acid induced excitotoxic lesions of the striatum are typically unilateral. This lesion does not compromise the animal's ability to feed and clean itself, but produces consistent impairments in contralateral paw use, or deficits in responding in the contralateral space. The unilateral lesion model also permits the intact striatum to be used for histological control.

\section{CELL REPLACEMENT THERAPY IN ANIMAL MODELS OF HD}

Cell replacement therapy as a clinical method for repairing damage to the brain has grown out of the experimental work starting over three decades ago. Originally, scientific interest looking into transplantation date back to the work by Elizabeth Dunn in the early part of the twentieth century, highlighted several principal factors that are still recognized today to be critical in producing successful grafts, such as the age and identity of the donor tissue and the method and the region of delivery of the graft. After many decades of hiatus, studies into cell transplantation were revived in the early 1970s when Olson and colleagues performed intraocular grafts of neural tissue into animals. However, the modern era of intracerebral transplantation started in the late 1970s by Stenevi, Björklund, and Svendgaard with their work on catecholamine grafts into rodent forebrain (Stenevi et al., 1976). Equally important, animal models of neurodegenerative diseases started appearing in the 1970s: Ungerstedt developed the 6-hydroxydopamine based striatal dopamine depleting lesion as a rodent model for PD (Ungerstedt, 1971), whilst Coyle and Schwarcz lesioned striatal projection neurons by injecting excitotoxins into the striatum as a way of simulating HD pathology (Coyle and Schwarcz, 1976). Over the years, numerous additional improvements have been made in the surgical, cell preparation, and transplantation protocols of striatal cells grafted into the HD model (Fricker et al., 1996, 1997a,b; Nikkhah et al., 2009; Jiang et al., 2011).

Selecting the type of cells for transplantation is influenced by multiple factors, including availability, safety, ethics, the disposition of the damage, and the level of repair that is required. Whether or not a particular graft is able to reverse any functional impairment will depend on the characteristics of the cell, including its plastic properties. However, it must be a consideration when thinking about the choice of cells in order to be able to achieve maximum recovery from specific functional deficits. Understanding the mechanisms of action of a graft in a particular environment promotes more effective and efficient cell therapies. Importantly, even without any functional anatomical reconnection, cells placed at a strategic site can still act as a neurotransmitter, a neurotrophic factor, or as a neuroprotective agent.
Today, the best source of graft tissue comes from dissected primary embryos since they contain the phenotypically appropriate populations of neurons at the optimal stage of development for growth and establishment of afferent and efferent connections. However, there are major obstacles in the use of primary embryonic tissue for grafting in the clinic, including screening, storing, quality control, and standardization of cells obtained separately on each occasion, as well as the moral, ethical, and practical concerns associated with collection of the products of elective abortion. Increasing effort is, therefore, being put into investigating the use of alternative cell sources (for example, embryonic stem cells, neural stem cells, iPS) for cell replacement therapies in various types of neurodegenerative disease, or CNS damage, including HD. Examining the advantages and disadvantages of the novel experimental cells is out of the scope of this review and this has been done extensively elsewhere (Zietlow et al., 2008; Dunnett and Rosser, 2011; Nicoleau et al., 2011). The following section will look at the use of primary striatal embryonic tissue in restoring anatomically and functional the GABAergic circuitry in animal models of HD.

\section{ASSESSMENT OF CELL THERAPY STRATEGIES IN ANIMAL MODELS OF HD}

How is it determined whether the experimental intervention has been successful or not? In the case of preclinical cell-therapy studies in the context of HD, as well as in other disease models such as Parkinson' disease, there are typically two phases. Firstly, the graft-mediated behavioral and functional effects are assessed by testing the animals on various behavioral paradigms focusing on motor and/or cognitive performance. Secondly, following the sacrifice of the animals, the brain is prepared for thorough histological analysis that has as its objective the assessment of the graft, including survival, phenotype, and possible migration, afferent and efferent connections. Data generated over time in preclinical transplantation studies in the HD model show that primary rat embryonic striatal tissue (E13E15 WGE) can survive, anatomically integrate with the host and confer functional benefits on simple motor, sensorimotor, as well as on complex cognitive tasks (Brasted et al., 1999a,b; Döbrössy and Dunnett, 2007). Experimental evidence strongly suggests that the basis for the graft-mediated functional and behavioral recovery is founded on two main factors: appropriate anatomical and functional integration of the graft with the host.

\section{Morphological and anatomical assessment}

What happens to the embryonic striatal cells following grafting into a lesioned striatum, what they become and how well they integrate with the host is typically studied by various staining and image analysis protocols, but can also be approached by in vivo push-pull perfusion or non-invasive imaging methods, for example. The morphology and its cellular composition of the graft is an essential part of all investigations (Figures $\mathbf{2 A - L}$ ). Typically, E13-E15 WGE are used as the source of cells for grafting as this tissue contains the progenitor cells that differentiate into striatal projection neurons (mainly medium spiny striatal neurons), as well as interneurons. However, at this stage 


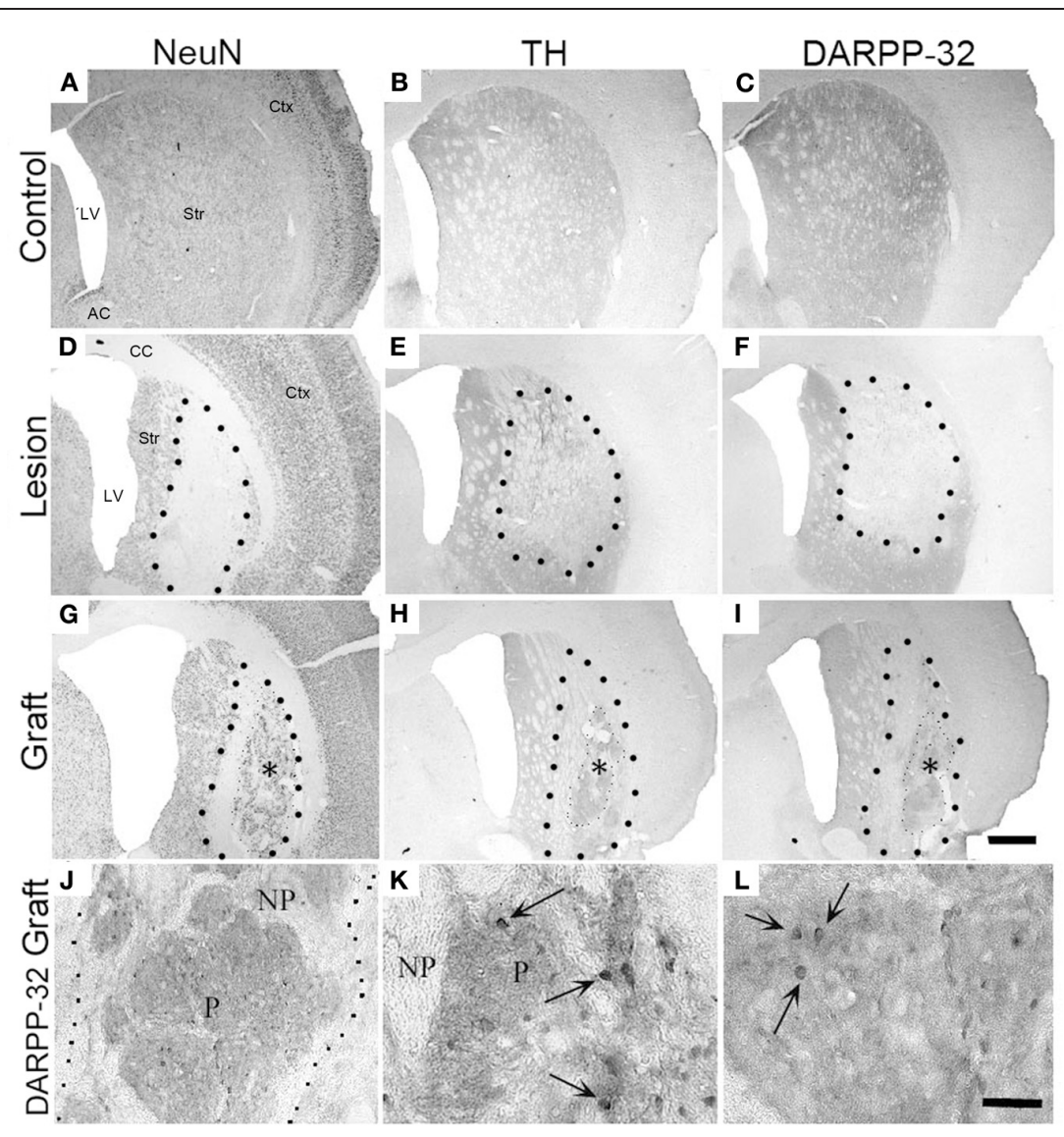

FIGURE 2 | Unilateral striatal quinolinic acid lesion and fetal cell transplantation. Photomicrographs illustrate sections from the control, the lesion, and the graft. Groups were stained with a neuron specific stain (NeuN; A, D, G), with a dopaminergic marker (tyrosine-hydroxylase; B, E, H), or for striatal-like tissue (DARPP-32; C, F, I). (A-C) The controls show regular staining without any deformation. (D-G) The enlarged ventricles, the necrotic core, and the reduction of staining in the striatum are apparent on the lesioned sections. (G-I) The grafted striatal tissue $\left({ }^{*}\right)$ survived in the lesioned striatum with striatal-like neurons aggregating into patches $\mathbf{( H , ~ I ) . ~ L a r g e r ~ b l a c k ~}$ dots delineate lesioned vs. intact striatum interface; smaller black dots show graft vs. host interface. (J-L) High magnification images of DARPP-32 positive cells from the P-zone of grafted animals. Arrows indicate individual DARPP-32 positive grafted neurons. Histology was done 35 weeks post-grafting. $\mathrm{P}$, patch; NP, non-patch. Scale bar in I = $1 \mathrm{~mm}$; scale bar in $\mathrm{L}=$ $20 \mu \mathrm{m}$. Str, striatum; CC, corpus callosum; LV, lateral ventricle; Ctx, cortex; AC, anterior commissure. Adapted from Döbrössy and Dunnett (2005). of the developing WGE, there are also progenitor cells for future cortical and pallidal neurons, which explain the heterogeneous composition of the grafts. The distinction between the striatal and non-striatal populations is done by staining the grafts for the presence of DARPP-32, which is used as a marker for the striatal-like neurons in the graft. Graft areas staining positive for DARPP-32 are known as P-zones ("P" for patch), whilst areas remaining negative are referred as NP zones ("NP" for non-patch) (Figures 2J-L). Various other markers can be used to visualize the P-zones, including AChE (striatal interneurons), tyrosine hydroxylase (TH, stains the dopaminergic inputs on the graft which are exclusive found on the striatal-like part of the graft). P-zones represent "islands" in otherwise NP-sections of the graft, and that the striatal-like cells are not randomly scattered around in the graft. This suggests that the striatal-like cells in the singlecell suspension or after the transplantation, form clusters and group together to establish zones of striatal-like cells excluding the other neuronal types to result in the $\mathrm{P}$ and NP patterns observed.
The striatal projection neurons are GABAergic, but a subset of them also co-expresses Substance P, Enkephalin, and Calbindin. The graft itself is commonly identified with NeuN staining which labels up all the cells in the graft whether they are striatal or not. NeuN and DARPP-32 staining permits analysis of several crucial parameters associated with the graft and the lesion model such as graft volume, DARPP-32 positive cells, the proportion of $\mathrm{P}$ and NP-zones, etc. Anatomical integration and the restoration of GABAergic circuitry is supported by diverse evidence. Firstly, using antero- and retrograde tracing methods, as well as xenografts, it has been shown that the transplanted striatal tissue sends efferent projections to the host globus pallidus, andunder certain conditions - to the substantia nigra. Furthermore, the striatal grafts can receive afferent projections from the cortex, thalamus, substantia nigra, and the raphé nucleus (Wictorin et al., 1992). Secondly, electron microscopy data shows that thalamic and nigral inputs can make synaptic contacts with MSNs within the grafts (Clarke and Dunnett, 1993). Thirdly, activation of host nigral inputs to striatal grafts can stimulate GABA 
release from striatopallidal terminals in the globus pallidus in the grafted animal with the same temporal resolution as in the intact striatopallidal neurons (Sirinathsinghji et al., 1988).

\section{Functional and behavioral assessment}

Grafted cells could survive and integrate anatomically with the host neuronal circuitry, but without a functional impact on the animals' behavior, it would be difficult to argue for clinical translation. Functional impact of the cells can be measured by using a wide range of behavioral tasks. The unilaterally lesioned striatum into which the striatal grafts are placed receives input from different cortical areas, including motor, sensorimotor, and associative areas, and this is reflected in the diverse nature of deficits observed following striatal lesions in the rat (McGeorge and Faull, 1989). For example, dorsolateral striatal lesions selectively produce skilled forelimb deficits, whilst dorsoventral striatal lesions impair both skilled forelimb use and tongue reaching. Medial striatal lesions, receiving inputs mainly from the auditory and visual cortex, do not affect either measurement (Pisa, 1988; Whishaw et al., 1987; Pisa and Cyr, 1990; Fricker et al., 1996). In a choice reaction-time task, lateral and medial striatal lesions induce ipsilateral response bias and increase latency in response initiation, respectively (Brown and Robbins, 1989). Lesions of the anteromedial area of the striatum, a region that receives its afferents predominantly from associative, auditory, and visual cortices, induces deficits in delayed alternation, and spatial navigation tasks, for example, but leaves visual discrimination performance intact; however, lateral, particularly ventrolateral striatal lesions, destroying cortical afferents from sensorimotor areas, disrupt performance on complex visual stimulus-response habit tasks (Divac et al., 1978; Isacson et al., 1986).

Graft-associated functional recovery is typically assessed using manual tests; recovery on more sophisticated behaviors involving rule learning or goal-directed actions are assessed by operant behavior tasks needing more specialized equipment. There is a vast amount of data that suggests that embryonic E13-E15 striatal grafts can promote partial, or in some case complete, functional recovery in simple motor tasks (Isacson et al., 1984; Sanberg et al., 1986; Döbrössy and Dunnett, 1998, 2003), sensorimotor tasks (Döbrössy and Dunnett, 2005, 2006b, 2007), motor skills tasks (Döbrössy and Dunnett, 2005, 2006a; Dunnett et al., 1988), and in cognitive, learning and memory tasks (Isacson et al., 1986; Mayer et al., 1992; Döbrössy and Dunnett, 1998; Brasted et al., 1999a,b).

\section{OPTIMIZING TRANSPLANT-MEDIATED FUNCTIONAL RECOVERY}

As discussed in the previous section, striatal GABAergic cells when transplanted into the damaged striatum can survive and integrate, and even reverse some functional deficits. However, functional recovery is mostly partial, meaning that full recovery of the animals' capacity on more complex tasks is seldom. Also, except for some of the simplest behavioral tasks, such as drug-induced rotation, regaining some of the lost function following grafting can be time and training dependent. What are the mechanisms behind graft-mediated functional improvement, and what factors influence this process? Is it possible to positively impact on the anatomical integration and functional recovery by manipulating the grafted animals' post-grafting experience, or does graft-development follow a default pathway following transplantation? These issues concern the "plasticity" of the graft: its capacity to respond to the macro-environment by adapting its cellular, molecular, or morphological properties that might lead to improved functional brain repair. For example, recovering performance on complex tasks requires the (re-) establishment of afferent and efferent connections with the host brain which are appropriate to the particular function that needs to be restored. In addition, studies have shown that even circuit reconstruction may not be sufficient for full functional recovery, but the anatomical integration needs to be back-up by appropriate behavioral training that provides the opportunity for the animal to "relearn" the lost function using the graft as the neural substrate (Coffey et al., 1989; Mayer et al., 1992; Brasted et al., 1999a,b). Experimental evidence has accumulated supporting the hypothesis that experience and training play an important part in the plasticity of, and functional recovery provided by, neural grafts [for review see (Döbrössy and Dunnett, 2001)]. More specifically, a series of studies over the past few years were designed to shed light on the conditions and factors that impact upon the development of embryonic striatal tissue transplanted into a unilaterally lesion rat model of HD. In particular, data from our group strongly suggests that:

1. Experience prior to grafting can influence the cellular and morphological features of the grafts, in particular that of the functionally important DARPP-32 positive striatal-like neurons within the transplants. Data shows that a greater number of DARPP32 cells were present in the grafts of animals that received intensive unilateral training prior to grafting on the ipsilateral paw compared to those that were trained on the contralateral paw; this suggests that training can have both a positive and a negative effect and that timing and specificity plays a role (Döbrössy and Dunnett, 2005).

2. The features of embryonic striatal grafts can be influenced following transplantation by environmental complexity and training. Three aspects associated with striatal plasticity were examined: dendritic spine densities, cell volumes of the grafted neurons, and changes in the levels of BDNF. Functional recovery was seen in all grafted animals independent of the whether or not they were exposed to the enriched environment. However, at the level of morphological and cellular analysis, variations in the graft development were apparent subsequent to the differential housing and exercise regimes. Animals housed in the enriched environment had significantly more BDNF, a candidate substrate for influencing graft morphology and plasticity, and their grafts had both greater spine densities and larger cell volumes. The study gave a strong indication that environmental complexity is a factor that affects the plasticity of grafted cells in situ (Figures 3A-D) (Döbrössy and Dunnett, 2006b).

3. Both the duration of the exposure and the extent of differential housing can influence multiple parameters of grafted cell morphology. The factors acted either independently, e.g., on graft size, complementarily, e.g., on spine density, or had no distinctive effect, e.g., on lesion size (Döbrössy and Dunnett, 2008). 


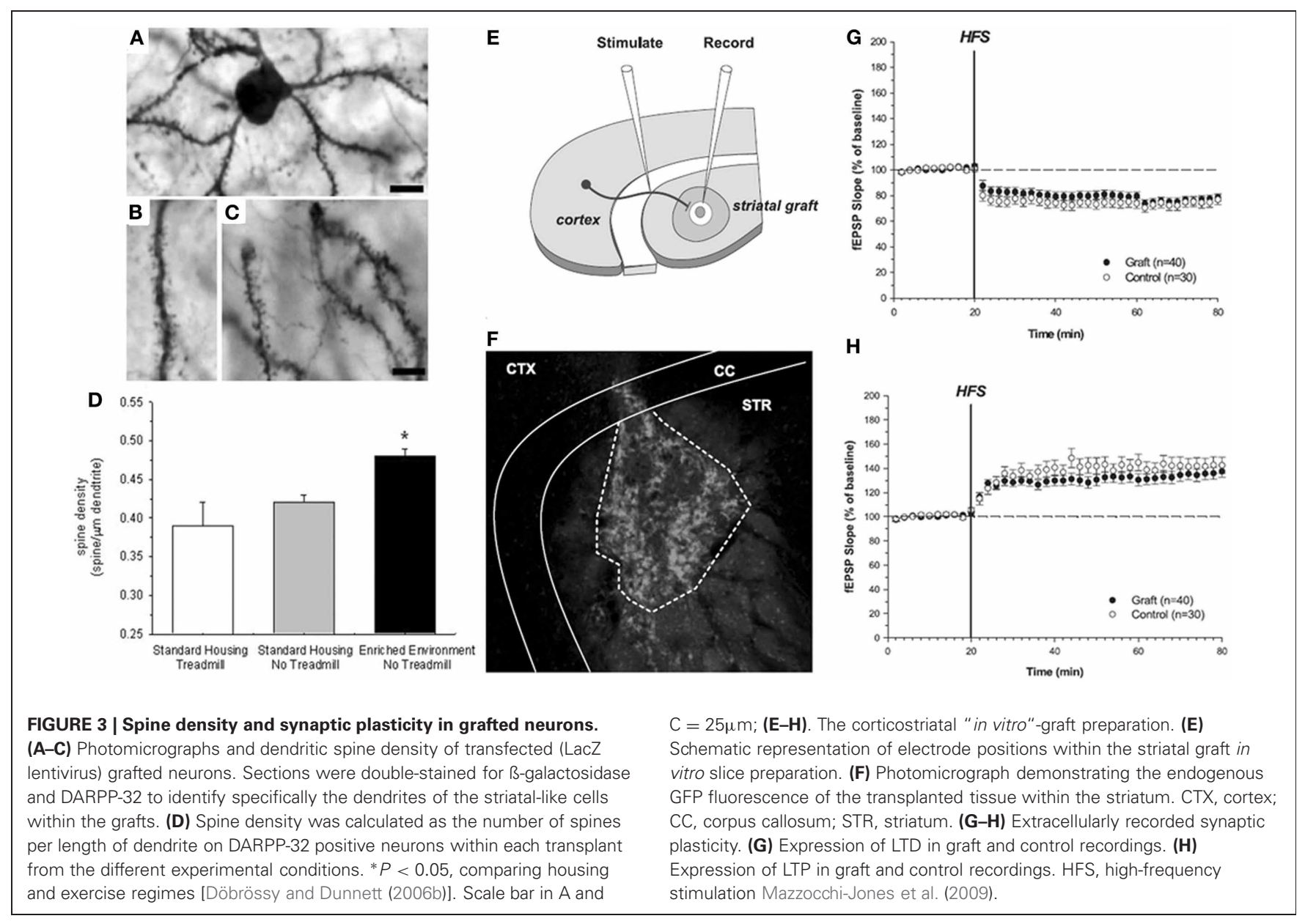

4. A possible source of the diversity in graft-induced behavioral recovery is individual differences between the experimental animals used. The data suggests that specific training of the paw controlled by the grafted striatum can influence the degree of graft-associated functional effect. The findings further demonstrated that grafts have the capacity to influence behavior, and importantly, the graft-effect was sensitive to experience and training (Döbrössy and Dunnett, 2006a).

5. Embryonic striatal grafts form functional connections with the host striatal circuitry, capable of restoring synaptic transmission and bi-directional synaptic plasticity, as evidenced by long-term potentiation and depression. Furthermore, environmental enrichment can facilitate the expression of long-term potentiation in the grafted striatum. Observing mechanisms of plasticity in the transplants, which can be influenced by environmental factors, suggests a high degree of physiological and functional integration and interaction between the transplant and the host. These results indicate that striatal grafts express synaptic correlates of learning, and thereby provide direct evidence of functional neuronal circuit repair, an essential component of "functional integration" (Figures 3E-H) (Mazzocchi-Jones et al., 2005, 2009, 2011).

In summary, the studies show that the development, including the morphological and cellular properties of embryonic striatal transplants, can be influenced by experience and the environment both prior and after transplantation into the host. The data suggest that neurorehabilitation should be a feature of clinical trials of cell transplantation in order to exploit the underlying mechanisms that promote anatomical integration of the grafted cells and maximize transplant-mediated functional recovery (Döbrössy et al., 2010).

\section{CLINICAL TRANSPLANTATION IN HD PATIENTS}

The previous sections summarize the experimental data from animal models of striatal degeneration and repair that served as rationale for clinical translation of cell-based therapy in HD: the functional and anatomical restoration of the damage and cell loss through the replacement of the degenerating cell by neuronal transplantation. Identifying optimal conditions leading to transplant-associated functional recovery and anatomical integration - producing appropriate spatial/temporal neurotransmitter release-is a key research target.

\section{OPEN LABEL TRIALS}

The first open label trials for clinical application of neurotransplantation in HD patients have been reported in the early 1990s, however, publications contained limited details on the functional outcome and the methodology used (Sramka et al., 1992; Madrazo et al., 1995). Results from a trial of bilateral 
stereotactic transplantation of isolated LGE tissue were reported in 1998 (Kopyov et al., 1998). Transplants in this trial were mechanically dissociated and derived from 5 to 8 foetuses of a CRL of 20 to $32 \mathrm{~mm}$. Deposits were localized within the caudate nucleus and to a smaller extend within the putamen, but the immunosuppressive regimen was not specified. Three patients were assessed according to the core assessment program for intracerebral transplantation in HD (CAPIT-HD). The investigators reported limited improvements in motor functions, as well as functional and behavioral improvements only in two patients, all measured using the UHDRS. However, the follow up period was only 12 months. Mechanically processed LGEtransplantation was used again in another clinical trial (Hauser et al., 2002). Immunosuppressive medication (Cyclosporin A) was administered for six months, and the suspension was again injected into the caudate and putamen. Clinical assessment was performed according to the CAPIT-HD protocol. The authors reported a slight clinical improvement in five of seven patients in motor and cognitive functions, but severe intracranial haemorrhage was described as a side effect in three patients. Longterm clinical data on the above mentioned trial was poorly documented.

Pre-clinical data suggests that transplantation of tissue from the WGE compared to LGE, provides better functional recovery. Basing on these experiments, a series of clinical trials were initiated using WGE tissue (Bachoud-Lévi et al., 2000; Rosser et al., 2002). In an open-label trial, five moderately-affected HD patients received human WGE tissue which was mechanically processed. A triple immunosuppression regimen (Cyclosporin A, Azathioprin, Prednisolon) was applied for more than 12 months (Bachoud-Lévi et al., 2000). Four out of five patients experienced improvement in cognitive and motor functions post-operatively during the initial follow up period of the first clinical report after two years. One patient worsened after cyst formation on one grafting site. A follow-up report comprising the long term clinical course six years after grafting described a slight worsening in three patients, which was more dominant in motor outcome than for cognitive improvement (Bachoud-Lévi et al., 2006). PET-scanning showed increased frontal and striatal glucose metabolism in three patients, which had an overall stable clinical course. The slight worsening in the three patients during the long-term clinical course was very limited, compared to the non-responding patients, and the WGE transplant was considered to modify the disease progression in a subgroup of patients.

The British "NEST-UK" consortium used a slightly different approach by transplanting cells derived from enzymatically dissociated human WGE, resulting in a higher level of cell separation at the time point of transplantation. From this study, a six-month follow-up report has been published that does not reveal any clinical changes at this early time-point (Rosser et al., 2002). A recent report on long-term outcome and PET-findings after grafting indicated stabilization and long-term improved metabolism in one patient 10 years after grafting, but also continuing clinical deterioration in a second patient who was transplanted with the same method (Reuter et al., 2008; Bachoud-Lévi, 2009). Ideally, data from a controlled trial would help in assessing the effectiveness of the treatment. Currently, there is an on-going clinical trial (MIG-HD trial) with a coordinating centre in Créteil, France, and affiliations in other French cities, Belgium, Italy, and Germany, and results of this trial are expected within the next 24 month. Similar efforts made for PD neurotransplantation already resulted in new disease insights and a better transplantation protocol that is now translated into the clinics within the EU-funded TRANSEURO network.

\section{GRAFT HISTOLOGY}

Published post mortem data from HD patients who died several years after grafting are mostly derived from LGE transplants. In a single case, a patient who participated in the pan-European MIG-HD-trial died six months after bilateral WGE grafting, representing the shortest time point after grafting so far. In this case, markers for on-going graft maturation (e.g., mitotic marker Ki67, neural stem cell marker Doublecortin, and Sox2) were detected in the graft (Capetian et al., 2009) and Figure 4A). In addition, DARPP-32 positive striatal projection neurons were found as well (Figure 4B). It could be shown that these grafted DARPP32 positive neurons are innervated by host-derived $\mathrm{TH}$ positive dopaminergic fibers as indicated by co-localization between $\mathrm{TH}$ and the synapse marker Synaptophysin (Figure 4B', *).

Published post-mortem data from HD-patient who deceased late after grafting is mostly originated from LGE transplants. Eighteen (Freeman et al., 2000), 74 and 79 months after transplantation (Keene et al., 2007), mature neuronal grafts expressing typical striatal projection-neuron and interneuronal markers and comprising typical striatal architecture of striosome and matrix were detected. In the very long-term surviving patients, the clinical deterioration might have been enhanced by perioperative complications mostly related to surgery. Using an unorthodox cotransplantation technique, combining grafting of a sural nerve with LGE tissue of four donors, the identification of compressing cyst formation and contralateral graft overgrowth has been found in a single case report evaluating the long-term (121 months) consequences of grafting of an HD patient (Keene et al., 2009). The authors found surviving neurons within the graft, but no characteristic MSNs were detected. In order to mediate the proposed therapeutic effect, appropriate graft connectivity involving both afferent and efferent synaptic connectivity, need to be assessed. Post-mortem data show that grafts in HD patients can receive dopaminergic (Freeman et al., 2000) and cortical glutamatergic (Cicchetti et al., 2009) input, but to date, there are no hints for graft efferents into the host brain.

The majority of reports examining post mortem grafts describe transplants which are spared from severe inflammatory reaction, often in contrast to the degenerating host brain (Capetian et al., 2011). A recent report has put forward contradictory evidence suggesting the possibility of pathology in the graft after examining post-mortem brains from three HD patients 9-10.5 years after transplantation (Cicchetti et al., 2009). Some graft-derived cells showed signs of neurodegeneration, e.g., expression of the apoptotic marker Caspase-3, host-derived inflammatory activation involving microglia and astrocytosis. These findings could be explained by general disease-associated neuroinflammation. 

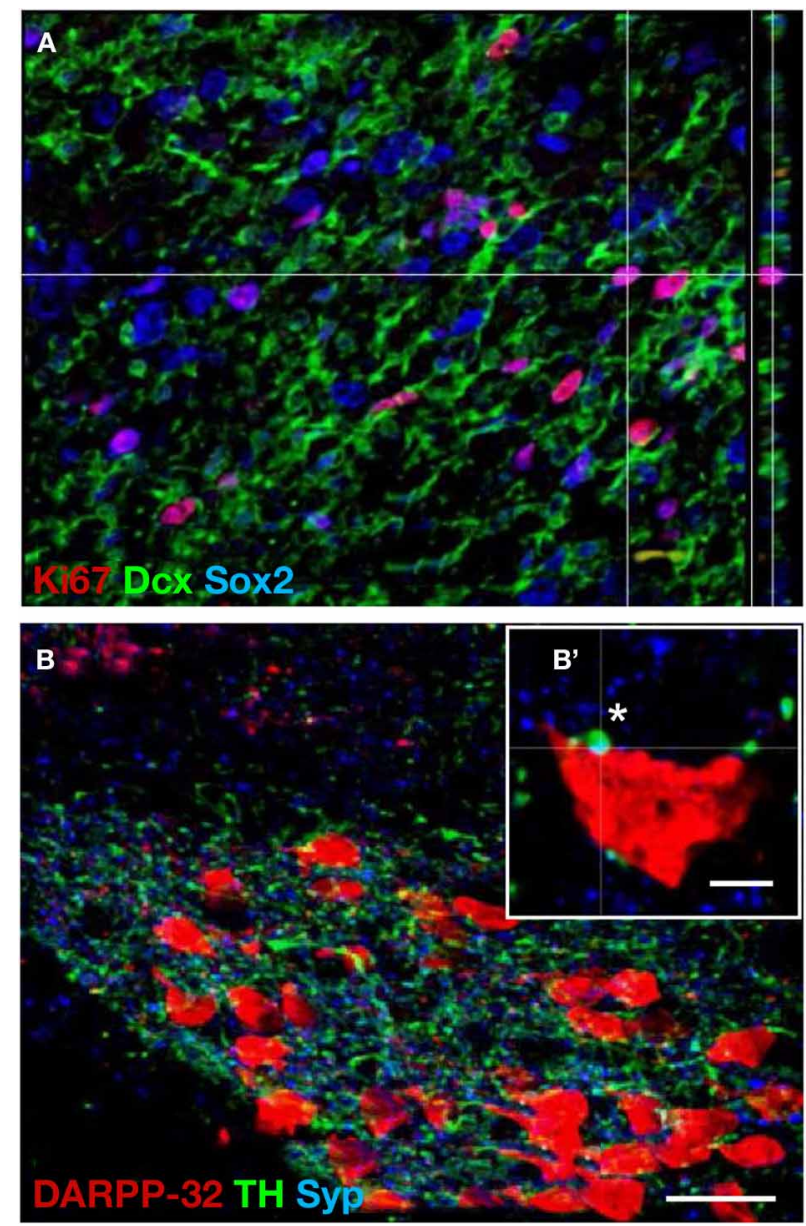

FIGURE 4 | Proliferation and integration of fetal striatal cells grafted in a HD brain. Photomicrographs illustrate human fetal WGE-derived graft in a post-mortem brain from a Huntington's disease patient six month post-grafting. (A) A large portion of the graft consists of proliferative neural precursor cells shown by co-immunohistochemical labeling of the mitotic marker Ki67 (red), and the neural stem cells markers Doublecortin (green) and Sox2 (blue). (B) The graft shows a striatal phenotype displayed by large aggregates of DARPP-32 positive neurons. These aggregates are surrounded by a dense network of dopaminergic TH positive fibers. ( $\mathbf{B}^{\prime}$ ) High magnification of a single graft-derived DARPP-32 positive neuron. A host-derived TH positive dopaminergic fiber forms a synapse with the grafted cell as shown by Synaptophysin co-labeling $(*)$. Dcx, Doublecortin; Syp, Synaptophysin. Scale bar in $B=30 \mu \mathrm{m}$, scale bar in $B^{\prime}=5 \mu \mathrm{m}$. Adopted from Capetian et al. (2009)

\section{ARE CLINICAL TRIALS IN HD A SUCCESS?}

During the last decade, several reports on functional outcome and post-mortem data of grafted HD patients were published. The functional outcome differs between trials. However, there are encouraging reports of patients displaying an improvement of cognitive and motor deficits. One major shortcoming at the interpretation of functional outcome is the lack of systematic assessment in the LGE-transplantation studies (Kopyov et al., 1998; Hauser et al., 2002). Comprehensive follow-up reports from the NEST-UK-cases, is still missing, and results from the ongoing MIG-HD-trial will not be available before 2013. Moreover, initial clinical reports described surgical complications in a significant higher number than in previous transplantation trials in PD (Wijeyekoon and Barker, 2011). On the other hand, methods applied in different trials are only rarely standardized between groups. In the past, tissue dissection methods varied between WGE transplantation and isolated transplants of the LGE. Tissue dissociation methods involved both mechanical and enzymatically methods. While for PD grafts, immune response is rarely discussed, the inflammatory host environment within the HD brain provides an environment more prone to evoke acute immune response, suggested by outcomes of acute graft rejection in an HD patient 14 month after grafting (Krystkowiak et al., 2007). Therefore, the optimal immune suppression remains to be determined.

Data from long-term-follow-up of PD patients after intracerebral grafting suggest clinical improvement to be a long-term effect which can take more than 10 years (Lindvall and Björklund, 2011), while HD pathology might progress in symptomatic patients, resulting in impaired graft-host-interaction and lack of graft projections. This might have an impact on patient selection, as it suggests implanting early stage patients with less inflammatory activity. After completing ongoing clinical transplantation programs, a critical reassessment of grafting techniques, patient selection criteria, tissue handling, and preparation and postoperative therapy including immunosuppression should come to pass.

\section{CONCLUSION}

The mosaic pattern of the adult striatum relies on two distinct anatomic characteristics: (1) the striosome and matrix subdivision and (2) the direct and indirect projection. The striosome/matrix subdivision is a result of striatal ontogeny. Striatum and globus pallidus originate from the WGE, a structure located in the ventral portion of the foetal telencephalon. During development, two waves of neurogenesis (early and late) can be observed in the WGE. Striosomal neurons are generated during the early neurogenesis between E12.5 and E14.5 in the rodent brain. Matrix neurons are generated during late neurogenesis which takes place between E17.5 and P2. In the adult brain, striosome and matrix neurons can be distinguished according to their neurochemical markers and cortical afferents. The second, independent anatomic characteristic of the adult striatum refers to the projection targets of striatal MSN. Two distinct types of projections neurons have been described for the adult striatum: direct and indirect projection neurons. Neurons of the direct projection type project to the $\mathrm{SNr}$ and the GPi. They predominantly express dopamine-receptor type 1 as well as Substance P and Dynorphin as co-transmitter. Neurons of this type are activated by the release of dopamine from the SNr. Neurons of the indirect projection type also project to the $\mathrm{SNr}$ and $\mathrm{GPi}$, but additionally project to the GPe. Neurons of the indirect projection type express type 2 dopamine receptors which are inhibited once dopamine is released from the $\mathrm{SNr}$, and express Enkephalin as co-transmitter.

Striatal degeneration is a key feature in HD. HD is an autosomal dominant inherited disease that is caused by a triplet repeat expansion in the human htt gene. In the diseased brain, 
cognitive and motor functions are severely affected. Due to the relatively selective loss of striatal MSN, HD has come into consideration for cell therapeutic approaches. The concept behind this therapy is the transplantation of striatal precursor cells (derived from the foetal WGE) into the diseased striatum. Grafted precursors are thought to mature in the host brain and replace degenerated striatal neurons. In pre-clinical HD research, different animal models are established to study the pathology of the disease. These animal models can be grouped into genetically modified and lesion-induced models. Neural transplantation was successfully tested in HD animal models. Graft histology proved that transplanted precursor cells mature and integrate into the host striatum. Furthermore, behavioral assessment showed that grafted cells participate to the basal ganglia circuitry and enable functional recovery.

These promising results justified clinical transplantation trials on small groups of HD patients. The first open label trials revealed a positive outcome in subgroups of patients. Thus, a follow-up controlled clinical trial was initiated (MIG-HD trial). Since the trial is still on-going, no data on functional recovery are available. Post-mortem data suggest that the cells mature into neurons and acquire a striatal phenotype. Furthermore, grafted cells are innervated by host-derived cortical and nigral afferents. In the future, refinement of cell preparation and standardization of transplantation protocols might be necessary to increase clinical benefit.

Future prospects might also focus on the generation of striatal neurons from alternative cell sources. Many gene functions and molecular interactions involved in striatal neurogenesis were already elucidated. Based on that, embryonic stem cells and iPS were successfully differentiated into striatal neurons in vitro. Further investigations may involve the direct reprogramming of somatic cells into striatal neurons.

\section{REFERENCES}

Aubry, L., Bugi, A., Lefort, N., Rousseau, F., Peschanski, M., and Perrier, A. L. (2008). Striatal progenitors derived from human ES cells mature into DARPP32 neurons in vitro and in quinolinic acid-lesioned rats. Proc. Natl. Acad. Sci. U.S.A. 105, 16707-16712.

Bachoud-Lévi, A. C. (2009). Neural grafts in Huntington's disease: viability after 10 years. Lancet Neurol. 8, 979-981.

Bachoud-Lévi, A. C., Gaura, V., Brugières, P., Lefaucheur, J. P., Boissé, M. F., Maison, P., Baudic, S., Ribeiro, M. J., Bourdet, C., Remy, P., Cesaro, P., Hantraye, P., and Peschanski, M. (2006). Effect of fetal neural transplants in patients with Huntington's disease 6 years after surgery: a long-term follow-up study. Lancet Neurol. 5, 303-309.

Bachoud-Lévi, A. C., Rémy, P., Nguyen, J. P., Brugières, P., Lefaucheur, J. P., Bourdet, C., Baudic, S., Gaura, V., Maison, P., Haddad, B., Boissé M. F., Grandmougin, T., Jény, R., Bartolomeo, P., Dalla Barba, G., Degos, J. D., Lisovoski, F., Ergis, A. M., Pailhous, E., Cesaro, P., Hantraye, P., and Peschanski, M. (2000). Motor and cognitive improvements in patients with Huntington's disease after neural transplantation. Lancet 356, 1975-1979.

Baydyuk, M., Russell, T., Liao, G. Y., Zang, K., An, J. J., French Reichardt, L., and $\mathrm{Xu}, \mathrm{B}$. (2011). TrkB receptor controls striatal formation by regulating the number of newborn striatal neurons. Proc. Natl. Acad. Sci. U.S.A. 108, 1669-1674.
Beal, M. F. (1992). Role of excitotoxicity in human neurological disease. Curr. Opin. Neurobiol. 2, 657-662.

Beal, M. F. (1998). Mitochondrial dysfunction in neurodegenerative diseases. Biochim. Biophys. Acta 1366, 211-223.

Beal, M. F., Brouillet, E., Jenkins, B. G., Ferrante, R. J., Kowall, N. W., Miller, J. M., Storey, E., Srivastava, R., Rosen, B. R., and Hyman, B. T. (1993). Neurochemical and histologic characterization of striatal excitotoxic lesions produced by the mitochondrial toxin 3nitropropionic acid. J. Neurosci. 13, 4181-4192.

Beal, M. F., Ferrante, R. J., Swartz, K. J., and Kowall, N. W. (1991). Chronic quinolinic acid lesions in rats closely resemble Huntington's disease. J. Neurosci. 11, 1649-1659.

Beal, M. F., Kowall, N. W., Ellison, D. W., Mazurek, M. F., Swartz, K. J., and Martin, J. B. (1986). Replication of the neurochemical characteristics of Huntington's disease by quinolinic acid. Nature 321, 168-171.

Beal, M. F., Kowall, N. W., Swartz, K. J., Ferrante, R. J., and Martin, J. B. (1989). Differential sparing of somatostatin-neuropeptide $\mathrm{Y}$ and cholinergic neurons following striatal excitotoxin lesions. Synapse 3, 38-47.

Brasted, P. J., Watts, C., Robbins, T. W., and Dunnett, S. B. (1999a). Associative plasticity in striatal transplants. Proc. Natl. Acad. Sci. U.S.A. 96, 10524-10529.

Brasted, P. J., Watts, C., Torres, E. M., Robbins, T. W., and Dunnett,
S. B. (1999b). Behavioural recovery following striatal transplantation: effects of postoperative training and P-zone volume. Exp. Brain Res. 128, 535-538.

Brouillet, E., Jenkins, B. G., Hyman, B. T., Ferrante, R. J., Kowall, N. W., Srivastava, R., Roy, D. S., Rosen, B. R., and Beal, M. F. (1993). Age-dependent vulnerability of the striatum to the mitochondrial toxin 3-nitropropionic acid. J. Neurochem. 60, 356-359.

Brown, V. J., and Robbins, T. W. (1989). Elementary processes of response selection mediated by distinct regions of the striatum. J. Neurosci. 9, 3760-3765.

Caiazzo, M., Dell'Anno, M. T., Dvoretskova, E., Lazarevic, D., Taverna, S., Leo, D., Sotnikova, T. D., Menegon, A., Roncaglia, P., Colciago, G., Russo, G., Carninci, P., Pezzoli, G., Gainetdinov, R. R., Gustincich, S., Dityatev, A., and Broccoli, V. (2011). Direct generation of functional dopaminergic neurons from mouse and human fibroblasts. Nature 476, 224-227.

Capetian, P., Döbrössy, M., Winkler, C., Prinz, M., and Nikkhah, G. (2011). To be or not to be accepted: the role of immunogenicity of neural stem cells following transplantation into the brain in animal and human studies. Semin. Immunopathol. 33, 619-626.

Capetian, P., Knoth, R., Maciaczyk, J., Pantazis, G., Ditter, M., Bokla, L., Landwehrmeyer, G. B., Volk, B., and Nikkhah, G. (2009). Histological findings on fetal striatal grafts in a Huntington's disease patient early after transplantation. Neuroscience 160, 661-675.

Cenci, M. A., Whishaw, I. Q., and Schallert, T. (2002). Animal models of neurological deficits: how relevant is the rat? Nat. Rev. Neurosi. 3, 574-579.

Choi, D. W. (1987). Ionic dependence of glutamate neurotoxicity. J. Neurosci. 7, 369-379.

Cicchetti, F., Saporta, S., Hauser, R. A., Parent, M., Saint-Pierre, M., Sanberg, P. R., Li, X. J., Parker, J. R., Chu, Y., Mufson, E. J., Kordower, J. H., and Freeman, T. B. (2009). Neural transplants in patients with Huntington's disease undergo disease-like neuronal degeneration. Proc. Natl. Acad. Sci. U.S.A. 106, 12483-12488.

Clarke, D. J., and Dunnett, S. B. (1993). Synaptic relationships between cortical and dopaminergic inputs and intrinsic GABAergic systems within intrastriatal striatal grafts. J. Chem. Neuroanat. 6, 147-158.

Coffey, P. J., Lund, R. D., and Rawlins, J. N. (1989). Retinal transplantmediated learning in a conditioned suppression task in rats. Proc. Natl. Acad. Sci. U.S.A. 86, 7248-7249.

Corbin, J. G., Rutlin, M., Gaiano, N., and Fishell, G. (2003). Combinatorial function of the homeodomain proteins $\mathrm{Nkx} 2.1$ and Gsh2 in ventral telencephalic patterning. Development 130, 4895-4906.

Coyle, J. T., and Schwarcz, R. (1976). Lesion of striatal neurones with kainic acid provides a model for Huntington's chorea. Nature 263, 244-246. 
Crook, Z. R., and Housman, D. (2011). Huntington's disease: can mice lead the way to treatment? Neuron 69, 423-435.

Divac, I., Markowitsch, H. J., and Pritzel, M. (1978). Behavioral and anatomical consequences of small intrastriatal injections of kainic acid in the rat. Brain Res. 151, 523-532.

Döbrössy, M., Busse, M., Piroth, T., Rosser, A., Dunnett, S., and Nikkhah, G. (2010). Neurorehabilitation with neural transplantation. Neurorehabil. Neural Repair 24, 692-701.

Döbrössy, M. D., and Dunnett, S. B. (1998). Striatal grafts alleviate deficits in response execution in a lateralised reaction time task. Brain Res. Bull. 47, 585-593.

Döbrössy, M. D., and Dunnett, S. B. (2001). The influence of environment and experience on neural grafts. Nat. Rev. Neurosci. 2, 871-879.

Döbrössy, M. D., and Dunnett, S. B. (2005). Training specificity, graft development and graft-mediated functional recovery in a rodent model of Huntington's disease. Neuroscience 132, 543-552.

Döbrössy, M. D., and Dunnett, S. B. (2003). Motor training effects on recovery of function after striatal lesions and striatal grafts. Exp. Neurol. 184, 274-284.

Döbrössy, M. D., and Dunnett, S. B. (2006a). The effects of lateralized training on spontaneous forelimb preference, lesion deficits, and graft-mediated functional recovery after unilateral striatal lesions in rats. Exp. Neurol. 199, 373-383.

Döbrössy, M. D., and Dunnett, S. B. (2006b). Morphological and cellular changes within embryonic striatal grafts associated with enriched environment and involuntary exercise. Eur. J. Neurosci. 24, 3223-3233.

Döbrössy, M. D., and Dunnett, S. B. (2007). The corridor task: striatal lesion effects and graft-mediated recovery in a model of Huntington's disease. Behav. Brain Res. 179, 326-330.

Döbrössy, M. D., and Dunnett, S. B. (2008). Environmental housing and duration of exposure affect striatal graft morphology in a rodent model of Huntington's disease. Cell Transplant. 17, 1125-1134.

Dunnett, S. B., Isacson, O., Sirinathsinghji, D. J., Clarke, D. J., and Björklund, A. (1988).
Striatal grafts in rats with unilateral neostriatal lesions - III. Recovery from dopamine-dependent motor asymmetry and deficits in skilled paw reaching. Neuroscience 24, 813-820.

Dunnett, S. B., and Rosser, A. E. (2011). Clinical translation of cell transplantation in the brain. Curr. Opin. Organ Transplant. 16, 632-639.

Durieux, P. F., Schiffmann, S. N., and de Kerchove d'Exaerde, A. (2011). Targeting neuronal populations of the striatum. Front. Neuroanat. 5:40. doi: 10.3389/fnana.2011.00040

Freeman, T. B., Cicchetti, F., Hauser, R. A., Deacon, T. W., Li, X. J., Hersch, S. M. Nauert, G. M., Sanberg, P. R., Kordower, J. H., Saporta, S., and Isacson, O. (2000). Transplanted fetal striatum in Huntington's disease: phenotypic development and lack of pathology. Proc. Natl. Acad. Sci. U.S.A. 97, 13877-13882.

Fricker, R. A., Annett, L. E., Torres, E. M., and Dunnett, S. B. (1996a). The placement of a striatal ibotenic acid lesion affects skilled forelimb use and the direction of druginduced rotation. Brain Res. Bull. 41, 409-416.

Fricker, R. A., Barker, R. A., Fawcett, J. W., and Dunnett, S. B. (1996b) A comparative study of preparation techniques for improving the viability of striatal grafts using vital stains, in vitro cultures, and in vivo grafts. Cell Transplant. 5, 599-611.

Fricker, R. A., Torres, E. M., and Dunnett, S. B. (1997a). The effects of donor stage on the survival and function of embryonic striatal grafts in the adult rat brain. I. Morphological characteristics. Neuroscience 79, 695-710.

Fricker, R. A., Torres, E. M., Hume, S. P., Myers, R., Opacka-Juffrey, J., Ashworth, S., Brooks, D. J., and Dunnett, S. B. (1997b). The effects of donor stage on the survival and function of embryonic striatal grafts in the adult rat brain. II. Correlation between positron emission tomography and reaching behaviour. Neuroscience 79, 711-721.

Gerfen, C. R. (1989). The neostriatal mosaic: striatal patch-matrix organization is related to cortical lamination. Science 246, 385-388.

Gerfen, C. R. (1992). The neostriatal mosaic: multiple levels of compartmental organization. Trends Neurosci. 15, 133-139.

Hamasaki, T., Goto, S., Nishikawa, S., and Ushio, Y. (2003). Neuronal cell migration for the developmental formation of the mammalian striatum. Brain Res. Brain Res. Rev. 41, $1-12$.

Hauser, R. A., Furtado, S., Cimino, C. R., Delgado, H., Eichler, S. Schwartz, S., Scott, D., Nauert, G. M., Soety, E., Sossi, V., Holt, D. A., Sanberg, P. R., Stoessl, A. J., and Freeman, T. B. (2002). Bilateral human fetal striatal transplantation in Huntington's disease. Neurology 58, 687-695.

Heng, M. Y., Detloff, P. J., and Albin, R. L. (2008). Rodent genetic models of Huntington disease. Neurobiol. Dis. 32, 1-9.

Henshaw, R., Jenkins, B. G., Schulz, J. B., Ferrante, R. J., Kowall, N. W., Rosen, B. R., and Beal, M. F. (1994). Malonate produces striatal lesions by indirect NMDA receptor activation. Brain Res. 647, 161-166.

Isacson, O., Brundin, P., Kelly, P. A., Gage, F. H., and Björklund, A. (1984). Functional neuronal replacement by grafted striatal neurones in the ibotenic acidlesioned rat striatum. Nature 311, 458-460.

Isacson, O., Dunnett, S. B., and Björklund, A. (1986). Graftinduced behavioral recovery in an animal model of Huntington disease. Proc. Natl. Acad. Sci. U.S.A. 83, 2728-2732.

Jiang, W., Büchele, F., Papazoglou, A., Döbrössy, M., and Nikkhah, G. (2011). Multi-tract microtransplantation increases the yield of DARPP32 positive embryonic striatal cells in a rodent model of Huntington's disease. Cell Transplant. 20, 15151527.

Kawaguchi, Y. (1997). Neostriatal cell subtypes and their functional roles. Neurosci. Res. 27, 1-8.

Kawaguchi, Y., Wilson, C. J., Augood, S. J., and Emson, P. C. (1995). Striatal interneurones: chemical, physiological and morphological characterization. Trends Neurosci. 18, 527-535.

Keene, C. D., Chang, R. C., Leverenz, J. B., Kopyov, O., Perlman, S., Hevner, R. F., Born, D. E., Bird, T. D., and Montine, T. J. (2009). A patient with Huntington's disease and long-surviving fetal neural transplants that developed mass lesions. Acta Neuropathol. 117, 329-338.

Keene, C. D., Sonnen, J. A., Swanson, P. D., Kopyov, O., Leverenz, J. B., Bird, T. D., and Montine, T. J. (2007). Neural transplantation in Huntington disease: long-term grafts in two patients. Neurology 68 2093-2098.
Kopyov, O. V., Jacques, S., Lieberman, A., Duma, C. M., and Eagle, K. S. (1998). Safety of intrastriatal neurotransplantation for Huntington's disease patients. Exp. Neurol. 149, 97-108.

Krushel, L. A., Fishell, G., and van der Kooy, D. (1995). Pattern formation in the mammalian forebrain: striatal patch and matrix neurons intermix prior to compartment formation. Eur. J. Neurosci. 7, 1210-1219.

Krystkowiak, P., Gaura, V., Labalette, M., Rialland, A., Remy, P. Peschanski, M., and Bachoud-Lévi, A. C. (2007). Alloimmunisation to donor antigens and immune rejection following foetal neural grafts to the brain in patients with Huntington's disease. PloS One 2:e166. doi: 10.1371/journal.pone.0000166

Lau, A., and Tymianski, M. (2010). Glutamate receptors, neurotoxicity and neurodegeneration. Pflügers Arch. 460, 525-542.

Lindvall, O., and Björklund, A. (2011). Cell therapeutics in Parkinson's disease. Neurotherapeutics 8, 539-548.

Long, J. E., Cobos, I., Potter, G. B., and Rubenstein, J. L. R. (2009a). Dlxland 2 and Mash1 transcription factors control MGE and CGE patterning and differentiation through parallel and overlapping pathways. Cereb. Cortex 19(Suppl. 1), i96-i106.

Long, J. E., Swan, C., Liang, W. S., Cobos, I., Potter, G. B., and Rubenstein, J. L. R. (2009b) Dlxland2 and Mash1 transcription factors control striatal patterning and differentiation through parallel and overlapping pathways. J. Comp. Neurol. 512, 556-572.

Madrazo, I., Franco-Bourland, R. E., Castrejon, H., Cuevas, C., and Ostrosky-Solis, F. (1995). Fetal striatal homotransplantation for Huntington's disease: first two case reports. Neurol. Res. 17, 312-315.

Marín, O., and Rubenstein, J. L. (2001). A long, remarkable journey: tangential migration in the telencephalon. Nat. Rev. Neurosci. 2, 780-790.

Marin, O., Anderson, S. A., and Rubenstein, J. L. (2000). Origin and molecular specification of striatal interneurons. J. Neurosci. 20, 6063-6076.

Martynoga, B., Morrison, H., Price, D. J., and Mason, J. O. (2005). Foxg1 is required for specification of ventral telencephalon and 
region-specific regulation of dorsal telencephalic precursor proliferation and apoptosis. Dev. Biol. 283, 113-127.

Matamales, M., Bertran-Gonzalez, J., Salomon, L., Degos, B., Deniau, J. M., Valjent, E., Hervé, D., and Girault, J. A. (2009). Striatal medium-sized spiny neurons: identification by nuclear staining and study of neuronal subpopulations in BAC transgenic mice. PloS One 4:e4770. doi: 10.1371/journal.pone.0004770

Mayer, E., Brown, V. J., Dunnett, S. B., and Robbins, T. W. (1992). Striatal graft-associated recovery of a lesion-induced performance deficit in the rat requires learning to use the transplant. Eur. J. Neurosci. 4, 119-126.

Mazzocchi-Jones, D., Döbrössy, M. D., and Dunnett, S. B. (2005). "Striatal grafts and synaptic plasticity," in Basal Ganglia VIII, eds J. P. Bolam, C. A. Ingham, P. J. Magill (New York, NY: Springer), 313-320.

Mazzocchi-Jones, D., Döbrössy, M. D., and Dunnett, S. (2011). Environmental enrichment facilitates long-term potentiation in embryonic striatal grafts. Neurorehabil. Neural Repair.

Mazzocchi-Jones, D., Döbrössy, M. D., and Dunnett, S. (2009). Embryonic striatal grafts restore bi-directional synaptic plasticity in a rodent model of Huntington's disease. Eur. J. Neurosci. 30, 2134-2142.

McGeorge, A. J., and Faull, R. L. (1989). The organization of the projection from the cerebral cortex to the striatum in the rat. Neuroscience 29, 503-537.

Le Moine, C., and Bloch, B. (1995). D1 and D2 dopamine receptor gene expression in the rat striatum: sensitive cRNA probes demonstrate prominent segregation of $\mathrm{D} 1$ and D2 mRNAs in distinct neuronal populations of the dorsal and ventral striatum. J. Comp. Neurol. 355, 418-426.

Nicoleau, C., Viegas, P., Peschanski, M., and Perrier, A. L. (2011). Human pluripotent stem cell therapy for Huntington's disease: technical, immunological, and safety challenges. Neurotherapeutics. 8, 562-576.

Nikkhah, G., Rosenthal, C., Falkenstein, G., Roedter, A., Papazoglou, A., and Brandis, A. (2009). Microtransplantation of dopaminergic cell suspensions: further characterization and optimization of grafting parameters. Cell Transplant. 18, 119-133.
Nóbrega-Pereira, S., Kessaris, N., $\mathrm{Du}, \mathrm{T}$., Kimura, S., Anderson, S., A, and Marín, O. (2008). Postmitotic Nkx2-1 controls the migration of telencephalic interneurons by direct repression of guidance receptors. Neuron 59, 733-745.

Paek, H., Gutin, G., and Hébert, J. M. (2009). FGF signaling is strictly required to maintain early telencephalic precursor cell survival. Development 136, 2457-2465.

Passante, L., Gaspard, N., Degraeve, M., Frisén, J., Kullander, K., de Maertelaer, V., and Vanderhaeghen, P. (2008). Temporal regulation of ephrin/Eph signalling is required for the spatial patterning of the mammalian striatum. Development 135, 3281-3290.

Pfisterer, U., Wood, J., Nihlberg, K., Hallgren, O., Bjermer, L., Westergren-Thorsson, G. Lindvall, O., and Parmar, M. (2011). Efficient induction of functional neurons from adult human fibroblasts. Cell Cycle 10, 3311-3316.

Pisa, M. (1988). Motor functions of the striatum in the rat: critical role of the lateral region in tongue and forelimb reaching. Neuroscience 24, 453-463.

Pisa, M., and Cyr, J. (1990). Regionally selective roles of the rat's striatum in modality-specific discrimination learning and forelimb reaching. Behav. Brain Res. 37, 281-292.

Poitras, L., Ghanem, N., Hatch, G., and Ekker, M. (2007). The proneural determinant MASH1 regulates forebrain Dlx1/2 expression through the I12b intergenic enhancer. Development 134, 1755-1765.

Ramaswamy, S., McBride, J. L., and Kordower, J. H. (2007). Animal models of Huntington's disease. ILAR J. 48, 356-373.

Reuter, I., Tai, Y. F., Pavese, N., Chaudhuri, K. R., Mason, S., Polkey, C. E., Clough, C., Brooks, D. J., Barker, R. A., and Piccini, P. (2008). Long-term clinical and positron emission tomography outcome of fetal striatal transplantation in Huntington's disease, $J$. Neurol. Neurosurg. Psychiatry 79, 948-951.

Roitberg, B. Z., Emborg, M. E., Sramek, J. G., Palfi, S., and Kordower, J. H. (2002). Behavioral and morphological comparison of two nonhuman primate models of Huntington's disease. Neurosurgery 50, 137-145. discussion 145-146.
Ross, C. A., and Tabrizi, S. J. (2011). Huntington's disease: from molecular pathogenesis to clinical treatment. Lancet Neurol. 10 83-98.

Rosser, A. E., Barker, R. A., Harrower, T., Watts, C., Farrington, M., Ho, A. K., Burnstein, R. M., Menon, D. K., Gillard, J. H., Pickard, J., and Dunnett, S. B. (2002). Unilateral transplantation of human primary fetal tissue in four patients with Huntington's disease: NEST-UK safety report ISRCTN no 36485475 . J. Neurol. Neurosurg. Psychiatry 73 , 678-685.

Sanberg, P. R., Henault, M. A., and Deckel, A. W. (1986). Locomotor hyperactivity: effects of multiple striatal transplants in an animal model of Huntington's disease. Pharmacol. Biochem. Behav. 25, 297-300.

Schwarcz, R., Foster, A. C., French, E. D., Whetsell, W. O., and Köhler, C. (1984). Excitotoxic models for neurodegenerative disorders. Life Sci. $35,19-32$.

Schwarcz, R., Fuxe, K., Hökfelt, T., Terenius, L., and Goldstein, M. (1980). Effects of chronic striatal kainate lesions on some dopaminergic parameters and enkephalin immunoreactive neurons in the basal ganglia. J. Neurochem. 34, 772-778.

Schwarcz, R., Hökfelt, T., Fuxe, K., Jonsson, G., Goldstein, M., and Terenius, L. (1979). Ibotenic acidinduced neuronal degeneration: a morphological and neurochemical study. Exp. Brain Res. 37, 199-216.

Schwarcz, R., Whetsell, W. O., and Mangano, R. M. (1983). Quinolinic acid: an endogenous metabolite that produces axon-sparing lesions in rat brain. Science 219, 316-318.

Shimamura, K., and Rubenstein, J. L. (1997). Inductive interactions direct early regionalization of the mouse forebrain. Development 124 2709-2718.

Sirinathsinghji, D. J., Dunnett, S. B., Isacson, O., Clarke, D. J. Kendrick, K., and Björklund, A. (1988). Striatal grafts in rats with unilateral neostriatal lesions-II. In vivo monitoring of GABA release in globus pallidus and substantia nigra. Neuroscience 24 803-811.

Sramka, M., Rattaj, M., Molina, H., Vojtassák, J., Belan, V., and Ruzick $\iota$, E. (1992). Stereotactic technique and pathophysiological mechanisms of neurotransplantation in Huntington's chorea. Stereotact. Funct. Neurosurg. 58, 79-83.
Stenevi, U., Björklund, A., and Svendgaard, N. A. (1976). Transplantation of central and peripheral monoamine neurons to the adult rat brain: techniques and conditions for survival. Brain Res. 114, 1-20.

Tepper, J. M., and Bolam, J. P. (2004). Functional diversity and specificity of neostriatal interneurons. Curr. Opin. Neurobiol. 14, 685-692.

The Huntington's Disease Collaborative Research Group. (1993). A novel gene containing a trinucleotide repeat that is expanded and unstable on Huntington's disease chromosomes. Cell 72, 971-983.

Tymianski, M., Charlton, M. P., Carlen, P. L., and Tator, C. H. (1993). Source specificity of early calcium neurotoxicity in cultured embryonic spinal neurons. J. Neurosci. 13, 2085-2104.

Ungerstedt, U. (1971). Striatal dopamine release after amphetamine or nerve degeneration revealed by rotational behaviour. Acta Physiol. Scand. Suppl. 367, 49-68.

Vierbuchen, T., Ostermeier, A., Pang, Z. P., Kokubu, Y., Südhof, T. C., and Wernig, M. (2010). Direct conversion of fibroblasts to functional neurons by defined factors. Nature 463 , 1035-1041.

Wang, L. H., and Qin, Z. H. (2006). Animal models of Huntington's disease: implications in uncovering pathogenic mechanisms and developing therapies. Acta Pharmacol. Sin. 27, 1287-1302.

Whishaw, I. Q., Mittleman, G., Bunch, S. T., and Dunnett, S. B. (1987). Impairments in the acquisition, retention and selection of spatial navigation strategies after medial caudate-putamen lesions in rats. Behav. Brain Res. 24, 125-138.

Wictorin, K., Brundin, P., Sauer, H., Lindvall, O., and Björklund, A. (1992). Long distance directed axonal growth from human dopaminergic mesencephalic neuroblasts implanted along the nigrostriatal pathway in 6hydroxydopamine lesioned adult rats. J. Comp. Neurol. 323, 475-494.

Wijeyekoon, R., and Barker, R. A. (2011). The Current status of neural grafting in the treatment of Huntington's disease. a review. Front. Integr. Neurosci. 5:78. doi: 10.3389/fnint.2011.00078

Zhang, N., An, M. C., Montoro, D., and Ellerby, L. M. (2010). Characterization of human Huntington's disease cell model 
from induced pluripotent stem cells. PLoS Curr.2:RRN1193. doi: 10.1371/currents.RRN1193

Zietlow, R., Lane, E. L., Dunnett, S. B., and Rosser, A. E. (2008). Human stem cells for CNS repair. Cell Tissue Res. 331, 301-322.

Zuccato, C., Ciammola, A., Rigamonti, D., Leavitt, B. R., Goffredo, D., Conti, L., MacDonald, M. E., Friedlander, R. M., Silani, V.,
Hayden, M. R., Timmusk, T., Sipione, S., and Cattaneo, E. (2001). Loss of huntingtin-mediated BDNF gene transcription in Huntington's disease. Science 293, 493-498.

Conflict of Interest Statement: The authors declare that the research was conducted in the absence of any commercial or financial relationships that could be construed as a potential conflict of interest.

Received: 01 February 2012; paper pending published: 29 February 2012; accepted: 23 March 2012; published online: 19 April 2012.

Citation: Pauly M-C, Piroth T, Döbrössy $M$ and Nikkhah $G$ (2012) Restoration of the striatal circuitry: from developmental aspects toward clinical applications.
Front. Cell. Neurosci. 6:16. doi: 10.3389/ fncel.2012.00016

Copyright (c) 2012 Pauly, Piroth, Döbrössy and Nikkhah. This is an openaccess article distributed under the terms of the Creative Commons Attribution Non Commercial License, which permits non-commercial use, distribution, and reproduction in other forums, provided the original authors and source are credited. 